\title{
Epidemiology of Giant Cell Tumor in Dr. Hasan Sadikin General Hospital Bandung from 2010-2013
}

\author{
Kirtana Gunasegaran, ${ }^{1}$ M.Naseh Sajadi Budi Irawan, ${ }^{2}$ Anglita Yantiasetiasti ${ }^{3}$ \\ ${ }^{1}$ Faculty of Medicine Universitas Padjadjaran, ${ }^{2}$ Department of Orthopaedic and Traumatology \\ Faculty of Medicine, Universitas Padjadjaran/Dr. Hasan Sadikin General Hospital Bandung, \\ ${ }^{3}$ Department of Anatomical Pathology Faculty of Medicine Universitas Padjadjaran/Dr. Hasan \\ Sadikin General Hospital Bandung
}

\begin{abstract}
Background: Giant cell tumor (GCT) of bone is a primary bone tumor. It is commonly seen in South East Asia and found in female around 20-45 years old. The GCT mostly occurs in epiphysis around the knee. The patients normally suffer from pain, swelling, limitation of joint movement, and pathologic fracture. This study aimed to determine the epidemiology of GCT of the bone based on age, sex, location, type, metastases, and recurrence in Dr. Hasan Sadikin General Hospital Bandung.

Methods: A descriptive study with retrospective cohort using total sampling method was used to obtain 33 medical records of patients with GCT of bone in Department of Orthopedic \& Traumatology and Anatomical Pathology Dr. Hasan Sadikin General Hospital Bandung in the period of January 2010-December 2013.

Results: The GCT of bone was mostly found in female of 20 to 29 years old and around 32 years old in male. Distal femur will be the most common site while zygoma, mandibular vertebrae, proximal tibia were rare sites. Twenty nine cases were benign lesion and the rest ( 4 cases) were malignant. The probability of GCT of bone to metastasize to lungs was very low. Four recurrences occurred within a year.

Conclusions: The GCT of bone in male mostly occurs in the third and fourth decade of age. It is found around the knee, mostly benign, rarely metastasize to the lungs and recurrence happens within a year. [AMJ.2016;3(2):244-7]
\end{abstract}

Keywords: Bone, epidemiology, giant cell tumor

\section{Introduction}

Giant cell tumor of bone is an osteoclastic giant cell-rich tumor and it is also known as osteoclastoma. It is a type of primary tumor in which comprises about $4-5 \%$ of all bone tumors. ${ }^{1,2}$ Giant cell tumor (GCT) of bone is a benign but locally aggressive primary bone tumor which has significant tendency for local recurrence. ${ }^{3}$ It is a relatively common tumor happened in South East Asia especially in China which has an incidence about $20 \% .4,5$ Females are more dominant in having GCTs compared to males. ${ }^{1,6}$ The incidence of GCT is highest in 20-45 years old. About $85 \%$ of the tumor occurs in those who are older than 19 years with the highest incidence in the third decade of life.7 The GCT mostly happens in the end of long bones or metaepiphyseal location with extension to subchondral bone and nearly half of the lesion involve the region around the knee. 5,8

Patients with GCT normally present with pain and swelling on the affected region, maybe with limitation of joint movement and pathologic fracture. There are two types of GCT: benign and malignant. Benign is the most common type of GCT of bone whereas malignant GCTs are very rare. When it comes to malignant, it can be further divided into primary and secondary. The recurrence of the tumor depends on the type of surgical interventions, localization of tumor and its extension to soft tissues. ${ }^{9}$ It accounts about 15$50 \%$ of the cases. ${ }^{1}$ Rarely, GCT can metastasize to the pulmonary region and they only account about $2 \%$ of GCTs. ${ }^{1}$ Based on the background above, author is interested to find out about the epidemiology of GCT of bone based on age,

Correspondence: Kirtana Gunasegaran, Faculty of Medicine, Universitas Padjadjaran, Jalan Raya Bandung-Sumedang Km.21, Jatinangor, Sumedang, Indonesia, Phone: +62 87822004605 Email: kirtana14@gmail.com 
sex, location, type, metastases, recurrence and get a clear concept on the distribution of the disease.

\section{Methods}

This was a descriptive study with retrospective cohort using 33 medical records of GCT of bone patients at the Department of Orthopedic \& Traumatology and Anatomical Pathology Dr. Hasan Sadikin General Hospital Bandung. Total sampling method was used to take the samples. The inclusion criteria were those who had been diagnosed with GCT of bone from 1st January 2010 until 31st December 2013. Incomplete medical records were excluded.

The variables studied were age which was divided into six categories based on the decades, sex, location, type, metastases and recurrences of the tumor. After permission letter and ethical clearance were taken from the Health Research Ethics Committee Faculty of Medicine Universitas Padjadjaran, and Dr. Hasan Sadikin General Hospital Bandung, the data needed were recorded and classified accordingly to its variables using Microsoft Excel.

\section{Results}

There were 33 GCT of bone patients divided into different age categories. Based on the age category, the third decade had the highest frequency with 13 patients. The lowest frequency was in the range of first decade with 1 patient out of 33 patients who was a 9 year old female. Eighteen out of 33 patients were males (Table 1).

Distribution of GCT of bone patients were in different locations. The most common location based on the data taken was in distal femur (10 patients) and followed by proximal tibia with total of 9 patients. Thus, GCT of bone in 19 patients occurred at the common location which was situated around the knee region. The distal femur, proximal tibia, distal radius, and proximal humerus were normally affected site of GCT while, zygoma, mandibular, vertebrae and distal tibia were the rare sites (Table 2).

Most of the GCT of bone in the patients were benign with total 29 out of 33 patients. Malignant feature of typical GCT was rare. It was seen in only 4 people. However, there was no description of transformation from benign to malignant GCT of bone in the medical record but the patients were just diagnosed of having malignant GCT of bone (Table 2).
Table 1 Frequency of GCT of Bone Patient Based on Sex and Age

\begin{tabular}{lc}
\hline \multicolumn{1}{c}{ Variable } & Frequency $(\mathbf{N}=\mathbf{3 3})$ \\
\hline Age (years) & \\
$0-9$ & 1 \\
$10-19$ & 4 \\
$20-29$ & 13 \\
$30-39$ & 7 \\
$40-49$ & 4 \\
$>50$ & 4 \\
Sex & \\
Male & 18 \\
Female & 15 \\
\hline
\end{tabular}

There was only one patient out of 33 patients in which the GCT of bone metastasized to the lungs (Table 3).

Only 4 out of 33 patients with GCT of bone had recurrence after the tumor remission or after they underwent the primary treatment since GCT of bone became tendency to recur, the recurrence in the patients occurred within a year after the procedure (Table 4).

Table 2 Frequency of GCT of Bone Patient Based on Location and Type

\begin{tabular}{lc}
\hline \multicolumn{1}{c}{ Variable } & Frequency $(\mathbf{N}=\mathbf{3 3})$ \\
\hline Location & 1 \\
Zygoma & 1 \\
Mandibular & 1 \\
Vertebrae & 2 \\
Distal radius & 2 \\
Distal ulna & 2 \\
Ramus pubis & 10 \\
Distal femur & 1 \\
Distal tibia & 9 \\
Proximal tibia & 2 \\
Calcaneus & 2 \\
Pedis tarsal & \\
Type & 29 \\
Benign & 4 \\
Malignant &
\end{tabular}


Table 3 Frequency of GCT of Bone Patient Based on Metastases

\begin{tabular}{lcc}
\hline Metastases & Location & $\begin{array}{c}\text { Frequency } \\
(\mathbf{N = 3 3 )}\end{array}$ \\
\hline Yes & Lung & 1 \\
& others & 0 \\
No & & 32 \\
\hline
\end{tabular}

\section{Discussions}

According to this study, the highest frequency was found in 13 patients in the third decade of age. It was followed by fourth decade of age which consists of 7 people. Subsequently, about 20 out of 33 patients with GCT of bone were found in the third and fourth decade. This was because GCT occurred in a skeletally matured bone. Mostly the tumor occurred in those who were older than 19 years old with the highest incidence in the third decade of age. ${ }^{9}$ According to World Health Organization (WHO), most of the incidences occurred in patients between the ages of 20-45 years old. There is only one female patient in the first decade of age with GCT of bone. The case is occurred due to arare occurrence in immature skeleton. ${ }^{1}$

There is a higher number of male patients diagnosed with GCT of bone compared to female with the ratio of 1.2:1. However, in other study, the GCT of bone is more prone to female compared to male with the ratio of 1.2:1. This is because females reach skeletal maturity 2 years in advance than male. ${ }^{10,11}$ Based on another study conducted by few doctors from a cancer hospital in Western India in 2007, it shows that males have apredominance of $57 \%{ }^{12}$

The most common location of GCT of bone is proximal tibia and followed by distal femur. This is because it mostly occurred in the epiphysis or metaepiphyseal location with extension to subchondral bone and the most

\section{Table 4 Frequency of GCT of Bone Patient} Based on Recurrence

\begin{tabular}{lcc}
\hline Recurrence & $\begin{array}{c}\text { Duration } \\
\text { (year) }\end{array}$ & $\begin{array}{c}\text { Frequency } \\
\text { (N=33) }\end{array}$ \\
\hline Yes & $<1$ & 4 \\
& $1-2$ & 0 \\
& $>2$ & 0 \\
No & & 29 \\
\hline
\end{tabular}

commonly affected region is the knee which was about 50-55 \%., In this study, the very rare site of GCT of bone even occurs in one patient each, affecting zygoma, mandibular, vertebrae and distal tibia. Besides that, there are only four patients with GCT affecting the rare site, the bones of the feet. It is documented by WHO that less than $5 \%$ of GCTs affects the tubular bones of both hands and feet. ${ }^{1}$

In this study, the benign type of GCT of bone is the most common, that is 29 patients compared to malignant GCT of bone that has only four patients. This is because the malignant-formed tumor is very rare.13,14 Three patients out of four with malignant GCTs are male. However, in this study, the patients were diagnosed with malignant GCT of bone but the transformation of the GCT of bone from benign to malignant was unclarified.

The GCT of bone metastasized only in one male patient out of 33 patients in accordance with the clinical information of the medical record of this study and the lungs is the common site for GCT of bone to metastasize because of the systemic spread. ${ }^{15}$ Recurrence rate of the tumor occurs in patients with GCT of bone and after they underwent the treatment. It is reported that most of the recurrence occurred within two years following the treatment. ${ }^{3}$ Based on this study, it is found that four patients who are two males and two females have recurrence of GCT of bone within one year. Recurrences depend on the type of surgical interventions, localisation of tumor and its extension to soft tissues. ${ }^{9}$

In conclusion, GCT of bone patients occurs mostly in the third and fourth decade of age. Male is more prone to GCT of bone compared to females. Furthermore, the knee region is the most common site for this tumor to occur. GCT of bone is mostly in benign form and the probability of it to metastasize is very low. Even if it metastasizes, it commonly goes to the lungs. The recurrence rate for GCT of bone occurs within a year in four out of 33 patients according to this study.

Due to limited time, the medical records of GCT of bone are only collected from 1st January 2010 until 31st December 2013 and are not taken from wide range of years. Beside that, the recurrence status of patients with GCT will be unknown unless they have been followed up for few months or years after the treatment.

As the recommendations, the epidemiology of GCT of bone should be known especially for those who are in their second or third decades and females should be aware of their risk of 
having GCT of bone and thus take precaution and seek early treatment before it is too late.

Incomplete medical records results in insufficient information. Hence, good anamnesis, physical examinations, laboratory examinations and supporting evidences such as imaging studies should be done to get a better diagnosis and there are high chances for better management of the disease.

This study can be used for further descriptive studies on GCT of bone and this can assist the population of Bandung to get to know about the disease and become more aware.

\section{References}

1. Fletcher CD, Bridge JA, Hogendoom PC, Mertens F. Osteoclastic giant cell-rich tumors. In: WHO. WHO classification of Tumors of Soft Tissue and Bone. 4th ed. Lyon: International Agency for Research in Cancer; 2013. p. 319-22.

2. Bhatia S, Miszczyk L, Roelandts $M$, Nguyen TD, Boterberg T, Poortmans P, et al. Radiotherapy for marginally resected, unresectable or recurrent giant cell tumor of the bone: a rare cancer network study. Rare Tumors. 2011;3(4):e48.

3. Saikia KC, Bhattacharyya TD, Bhuyan SK, Bordoloi B, Durgia B, Ahmed F. Local recurrences after curettage and cementing in long bone giant cell tumor. Indian J Orthop. 2011;45(2):168-73.

4. Niu X, Zhang Q, Hao L, Ding Y, Li Y, Xu H, et al. Giant cell tumor of the extremity retrospective analysis of 621 Chinese patients from one institution. J Bone Joint Surg Am. 2012;94(5):461-7.

5. Saikia KC, Bhuyan SK, Borgohain M, Saikia SP, Bora A, Ahmed F. Giant cell tumour of bone: an analysis of 139 Indian patients. J Orthop Sci. 2011;16(5):581-8.
6. Chakarun CJ, Forrester DM, Gottsegen CJ, Patel DB, White EA, Matcuk GR. Giant cell tumor of bone: review, mimics, and new developments in treatment. Radiographics. 2013;33(1):197-211.

7. Unni KK, Inwards CY. Giant cell tumor (Osteoclastoma). In: Unni KK, Inwards CY. Dahlin's Bone Tumors. 6th ed. Philadelphia: Lippincott William \& Wilkins; 2010. p. 225-42.

8. Muramatsu K, Ihara K, Taguchi T. Treatment of giant cell tumor of long bones: clinical outcome and reconstructive strategy for lower and upper limbs. Orthopedics. 2009;32(7):491-501.

9. Heijden LV, Dijkstra PS, Sande MV, Hogendoorn PC, Kroep JR, Nout RA, et al. The clinical approach toward giant cell tumor of bone. Oncologist. 2014;19(5):550-61.

10. Raskin KA, Schwab JH, Mankin HJ, Springfield DS, Hornicek FJ. Giant cell tumor of bone. J Am Acad Orthop Surg. 2013;21(2):118-26.

11. Federman N, Brien EW, Narasimhan V, Dry SM, Sodhi M, Chawla SP. Giant cell tumor of bone in childhood: clinical aspects and novel therapeutic targets. Pediatr Drugs. 2014;16(1):21-8.

12. Gupta R, Seethalakshmi V, Jambhekar NA, Prabhudesai S, Merchant N, Puri A, et al. Clinicopathologic profile of 470 giant cell tumors of bone from a cancer hospital in Western India. Ann Diagn Pathol. 2008;12(4): 239-48.

13. Kadowaki M, Yamamoto S, Uchio Y. Late malignant transformation of giant cell tumor of bone 41 years after primary surgery. Orthopedics. 2012;35(10):e156670.

14. Amanatullah DF, Clark TR, Lopez MJ, Borys D, Tamurian RM. Giant cell tumor of bone. Orthopedics. 2014;37(2):112-20. 